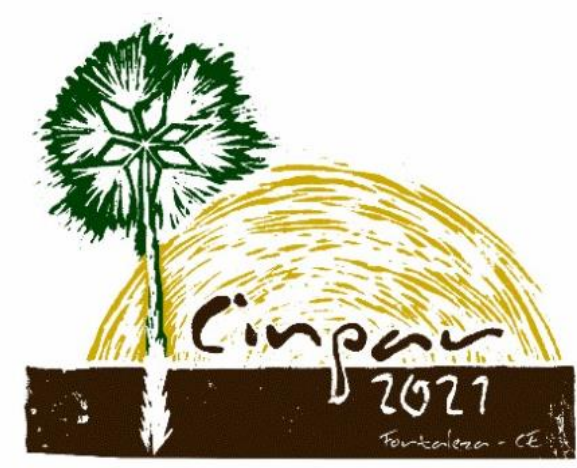

XVII Congresso Internacional sobre Patologia e Reabilitação das Construções

XVII Congreso Internacional sobre Patología y Rehabilitación de las Construcciones

XVII International Conference on Pathology and Constructions Rehabilitation

FORTALEZA (Brasil), 3 a 5 de junho de 2021 https://doi.org/10.4322/CINPAR.2021.114

\title{
LEVANTAMENTO DAS MANIFESTAÇÕES PATOLÓGICAS COM APLICAÇÃO DO GUT: ESTUDO DE CASO EM DUAS PONTES DE CONCRETO ARMADO EM CAXIAS/MA
}

\section{SURVEY OF PATHOLOGICAL MANIFESTATIONS WITH APPLICATION OF GUT: CASE STUDY IN TWO BRIDGES OF ARMED CONCRETE IN CAXIAS-MA}

\author{
Kelly Cristina Silva Santos ${ }^{1}$, Mikhael Ferreira da Silva Santos ${ }^{2}$, Cláudio Vidrih Ferreira ${ }^{211}$ \\ UNIFACEMA, Caxias, Brasil, kellycsantos95@gmail.com \\ ${ }^{2}$ UNIFACEMA, Caxias, Brasil, mikhael@ferreiraeng.com \\ ${ }^{3}$ Instituto Vidrih, Bauru/SP, Brasil, vidrih@vidrih.com.br
}

\begin{abstract}
Resumo: As manifestações patológicas em obras de arte se tornou um tema bastante explorado, principalmente devido os diversos acidentes envolvendos obras desse tipo. No municipio de Caxias, estado do Maranhão, diversas pontes apresentam um número significativo de manifestações patológicas associadas, muitas vezes, à execução inadequada, falta de planejamento e falta de manutenção preventiva. Nesse contexto, ocorre a deterioração da vida útil das pontes mencionadas. Percebe-se, infelizmente, que isso é uma realidade que prejudica não só as pontes de Caxias/MA, mas basicamente todas as obras públicas do país. Esse trabalho possui o escopo de determinar o grau de prioridade das manifestações patológicas, através do método GUT (Gravidade, Urgência e Tendência), em duas pontes de concreto armado situado no município de Caxias, estado do Maranhão: Pontes Eugênio Barros e Dr. Fernando Sarney. Foram realizadas vistorias de inspeção visuais e check-list nas aludidas pontes utilizando materiais como trena manual, escalímetro e câmera fotográfica. Foram constatadas trincas, fissuras e rachaduras, corrosão da armadura, desagregação, ninhos de concretagem, mofo, bolor e fungos. O tipo de manifestações com maior incidência foi a corrosão da armadura e a manifestação patológica com maior grau de prioridade, após a aplicação do método GUT, foram trincas, fissuras e rachaduras. Observou-se assim, que uma manifestação patológica pode originar danos tanto na parte estética das pontes, quanto em sua segurança estrutural, e assim necessitando da realização de inspeções mais aprofundadas, para que sejam capazes de controla os efeitos dos defeitos encontrados, a fim de prolongar a vida útil das pontes.
\end{abstract}

Palavras-chave: manifestações patólogicas; método Gut; pontes; obras públicas.

Keyword: pathological manifestations; Gut method; bridges; public works.

Abstract: 


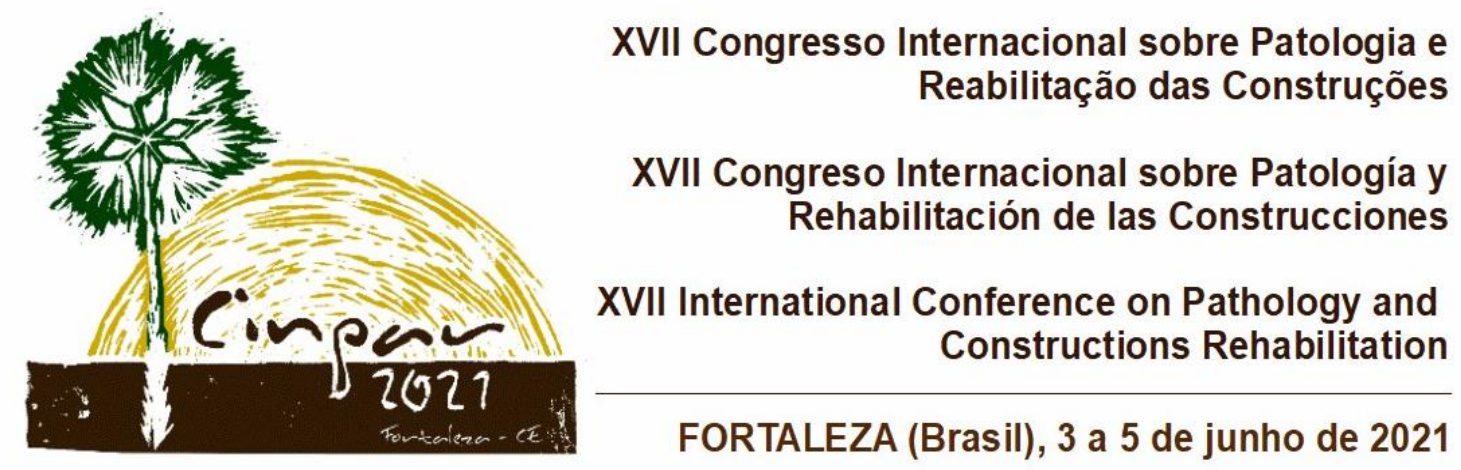

\section{Introdução}

No início das construções as pontes eram projetadas empiricamente e consideradas trabalhos de arte e nos tempos atuais ainda carregam consigo esse título de grandes obras da engenharia.

Ainda hoje, os arquitetos e engenheiros exploram a diversidade de formas e materiais disponíveis e conferem a essas obras, além de funcionalidade e beleza arquitetônica. No entanto, de forma geral, essas construções possuem como objetivo principal transpor obstáculos e dar continuidade às vias (PFEIL, 2005), sendo, por vezes, o único meio de ligação entre dois pontos.

Esses problemas, na área da engenharia, são estudados pela "Patologia das Construções", é uma ciência a qual objetiva estudar as origens, causas, mecanismos de ocorrência, manifestações e consequências dos problemas que afetam as pontes e sua vida útil (VIEIRA, 2016).

Dessa forma a Norma de Inspeção Predial Nacional do Instituto Brasileiro de Avaliações e Perícias de Engenharia-IBAPE (2012), aconselha que metodologias técnicas apropriadas como o método de gravidade, urgência e tendência- GUT, para classificar a ordem de prioridades.

É notório que a não realização da manutenção regular em obras públicas, objetiva esta pesquisa para fazer um estudo das manifestações patológicas, onde será empregado o método GUT (gravidade, urgência e tendência), de forma a observar e avaliar as condições nas quais encontra-se as pontes e através disso será fornecido dados que servirá para conduzir uma possível intervenção, para chegar até os órgãos responsáveis. Assim, são as inúmeras manifestações patológicas na construção civil, que também podem ser chamadas de deformações ou doenças anatômicas e funcionais que são provocadas nas pontes. Essas doenças muitas das vezes podem aparecer durante a execução do projeto, a falta do controle tecnológico, e principalmente no que se refere ao concreto, equipe sem preparação para a execução de projetos mais elaborados, falta de fiscalização por parte dos gestores ou responsáveis pela execução, e o tipo de material é de má qualidade, podem ocorrer na concepção do projeto e também essas patologias podem aparecer durante toda sua vida em consequência da falta de manutenção frequente, além dos fatores ambientais e atmosféricos, tem grande influência. Esses erros podem causar muitos problemas estéticos, onde irá ocasionar o aparecimento de manchas, rachaduras, trincas e as fissuras, onde resultará em um colapso estrutural. 


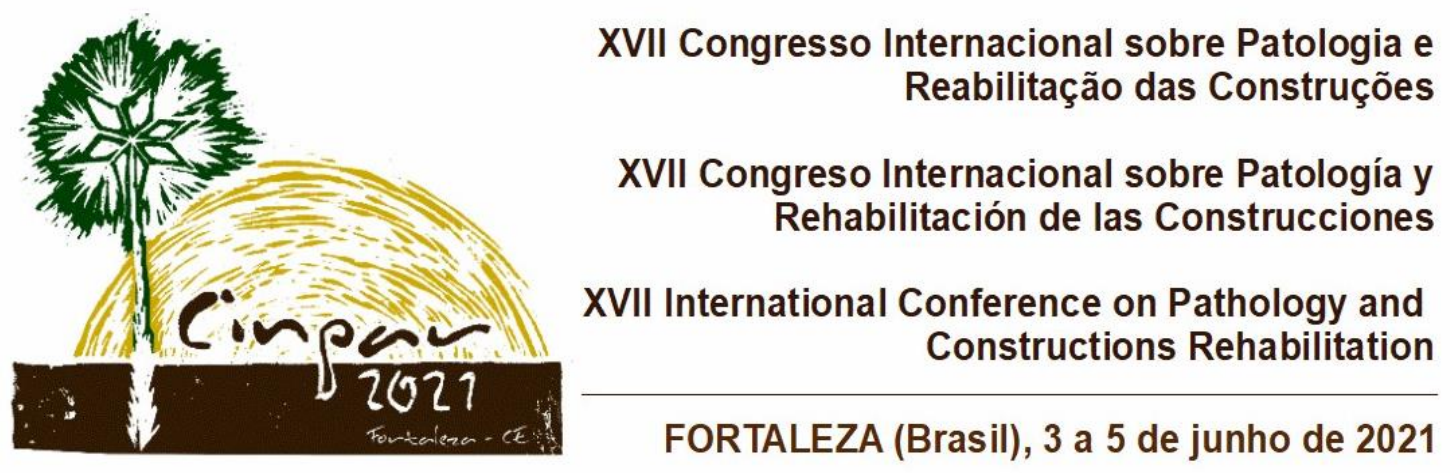

As patologias são diagnosticadas como danos causados nas construções, e com isso elaboramos um estudo no qual será sistemático para os acontecimentos e suas causas. Neste trabalho foi realizado uma pesquisa na ordem de priorização utilizando o método GUT, de forma a analisar e priorizar um levantamento sobre as patologias estruturais que foram identificadas na ponte de concreto armado na cidade de Caxias- MA aplicando o Método da Matriz de Gravidade, Urgência e Tendência (GUT), enfatizar um estudo bibliográfico sobre as patologias estruturais encontradas em ponte de concreto armado, explicar a metodologia análise GUT, realizar uma vistoria no local, com levantamento do histórico e análise do desempenho da ponte e fazer um estudo aprofundado sobre as patologias existentes na ponte, apontar os mecanismos que causam essas manifestações as quais estão causando as patologias.

Levando em consideração todo o desenvolvimento da pesquisa é suma importância, pois proporcionou dados a ser utilizado para orientar as intervenções e manutenções futuras que podem ocorrer na estrutura das pontes, isso visa melhorias nos aspectos funcionais que vai aumentando a vida útil e posteriormente garantir conforto e segurança para as pessoas que ali trafegam e também ajudando como sugestão a trabalhos futuros.

\section{Referencial Teórico}

\subsection{Histórico das pontes}

Segundo Marchetti (2018), entende-se que Ponte é uma obra destinada a permitir a transposição de obstáculos e serve para dá continuidade de uma via de comunicação qualquer. Como exemplos destes obstáculos pode-se citar: os rios, braços de mar, vales profundos, outras vias etc. Com o surgimento das primeiras pontes que veio de forma natural, como por exemplo um tronco de uma árvore, desde então veio a ideia de executar pontes de uma forma mais simples e feita dos próprios troncos ou de pranchas.

De acordo com Cavalcante (2019), pode-se observar que as pontes têm um grande fator de importância dentro da construção civil, pois a cada ano que passa são exigidas tecnologias mais inovadoras e mais criativas que venham a vencer os desafios que são impostos pelos fatores climáticos, arquitetônicos, geológicos, logísticos etc. 


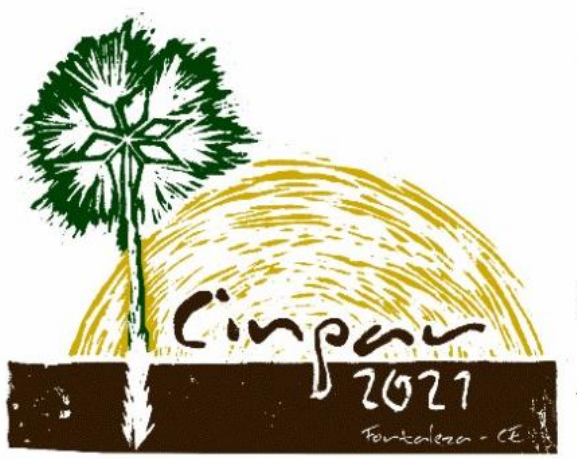

XVII Congresso Internacional sobre Patologia e
Reabilitação das Construções

XVII Congreso Internacional sobre Patología y

Rehabilitación de las Construcciones

XVII International Conference on Pathology and

Constructions Rehabilitation

FORTALEZA (Brasil), 3 a 5 de junho de 2021

É notório os diversos tipos de pontes e os vários tipos de materiais usados para fazer a sua execução. Antes as pontes eram construídas de pedras ou de madeira, atualmente esses dois tipos quase não são vistos em prática e as pontes mais vistas nos dias de hoje são: metálicas, de concreto armado ou concreto protendido; e tudo se deu com a evolução do concreto na engenharia.

\subsection{Pontes: aspectos estruturais}

A engenharia civil em modo geral acaba com âmbito de que as estruturas devem ser construídas ou projetadas de forma a atender as classificações das normas vigentes (NBR's). Para Marchetti (2008), destacase que o projeto de construção de Pontes é uma obra destinada a permitir o deslocamento de obstáculos como os braços de mar e os rios, sendo que são divididas em três partes: mesoestrutura, que são os pilares, encontros e aparelhos de apoio, a infraestrutura que fazem a representação das fundações, e a superestrutura, que representa as lajes e as vigas.

As pontes devem atender às condições de utilização para as quais foram dimensionadas, e com isso a capacidade de escoamento do tráfego de veículos será de acordo com o número de faixas, é necessário observar a necessidade ou não do passeio para que haja a circulação de pedestres, seu tempo de vida útil, e tudo isso será relacionado com as solicitações de tráfego ao longo do tempo, estabelecendo assim a sua funcionalidade. A Figura 1 mostra os elementos que indicam a composição das pontes em geral.

\subsection{Classificação das pontes}

Para Leonhardt (1979), as pontes tinham um modo para serem classificadas e parte era mediante aos materiais que eram empregados, a mesma na sua projeção. São empregadas inúmeras classificações para as pontes, que podem se destacar: quanto ao material da superestrutura, à natureza do tráfego, ao tempo de utilização e ao sistema estrutural. E, sem esquecer que em relação ao tipo de material empregado, elas podem ser de madeira, metálicas, de pedras ou de concreto (simples, armado ou protendido).

Figura 01- Esquema ilustrativo da composição de pontes 


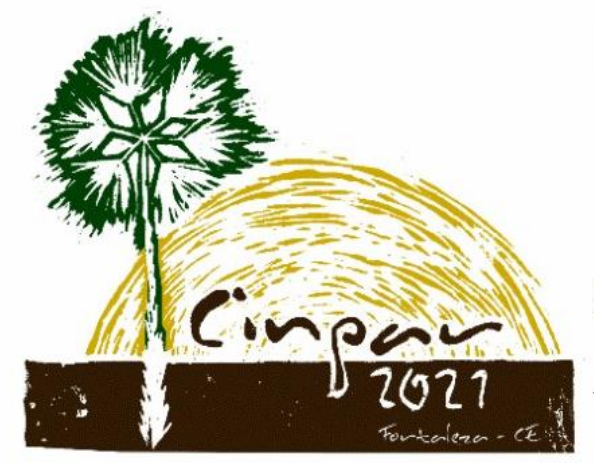

XVII Congresso Internacional sobre Patologia e
Reabilitação das Construções

XVII Congreso Internacional sobre Patología y Rehabilitación de las Construcciones

XVII International Conference on Pathology and Constructions Rehabilitation

FORTALEZA (Brasil), 3 a 5 de junho de 2021

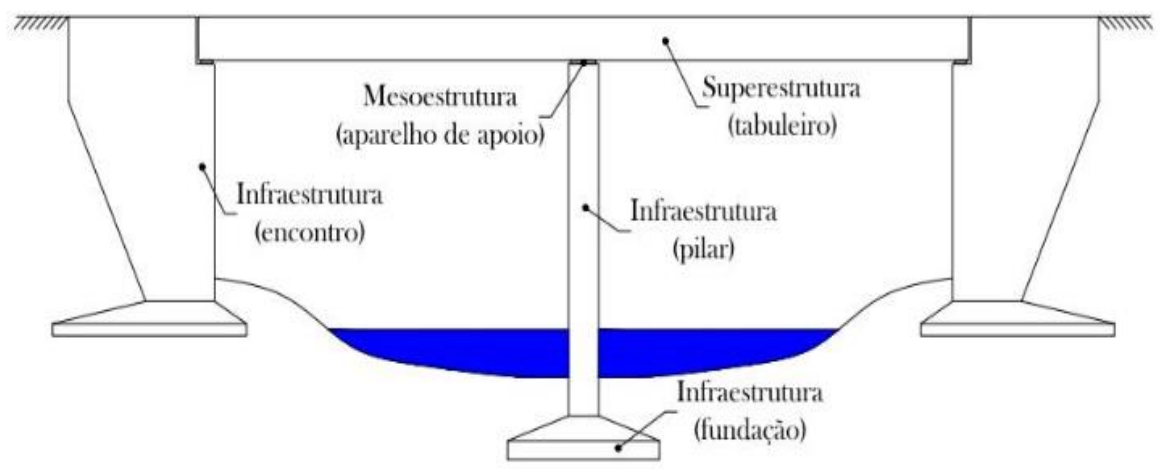

Fonte: Adaptada de El Debs e Takeya (2009)

Pode-se relacionar as pontes como ferrovias, aeroviárias, canal, mistas, aqueduto, passarelas e rodoviárias. Do mesmo modo, para o autor, as pontes rodoviárias possuem um tipo de sistema estrutural da superestrutura e que é baseado em cinco itens: vigas, pórticos, arco, pênseis e tirantes (MARCHETTI, 2008).

Em relação ao tempo para a utilização, as pontes são divididas em permanentes e provisórias. E, em termos estruturais elas podem ser em vigas, vigas de caixão, treliçadas, pórtico, arco ou suspensas por cabos (FELIPPE FILHO, 2008). As pontes podem ser executadas em peças-moldadas (pré-fabricadas) como mostra Marchetti (2008), as pré-moldadas são os elementos como somente as longarinas, e os demais elementos são moldados no local, e não são construídos na sua posição final, a moldagem pode ser em usinas fora do local da obra ou no próprio canteiro de obra. O sistema construtivo é empregado nas pontes de concreto protendido sendo moldadas no local onde vai utilizar o escoramento especifico para este fim, como cimbramento, treliça deslizante, apoiados sobre os pilares e formas para moldar o elemento de concreto (MARCHETTI, 2008).

A NBR 9062, ressalta que os elementos pré-moldados são confeccionados fora do local da obra, ou seja, em uma instalação provisória que será feita para este fim, enquanto os demais elementos préfabricados são produzidos comercialmente em uma instalação permanente (ABNT, 2017).

Uma forma que é bastante recomendada de concretagem de trechos é de 3 a 5 metros a cada 3 dias sendo que o utilizado nas pontes de concreto protendido de segmentos (em aduelas) tem um sistemas bastante similar, pois os balaços são sucessivos, mas as peças são pré-moldadas, e é bastante vantajoso quando a extensão da ponte é muito longa, e assim os trechos são projetados de 3 a $8 \mathrm{~m}$ de comprimento, e 


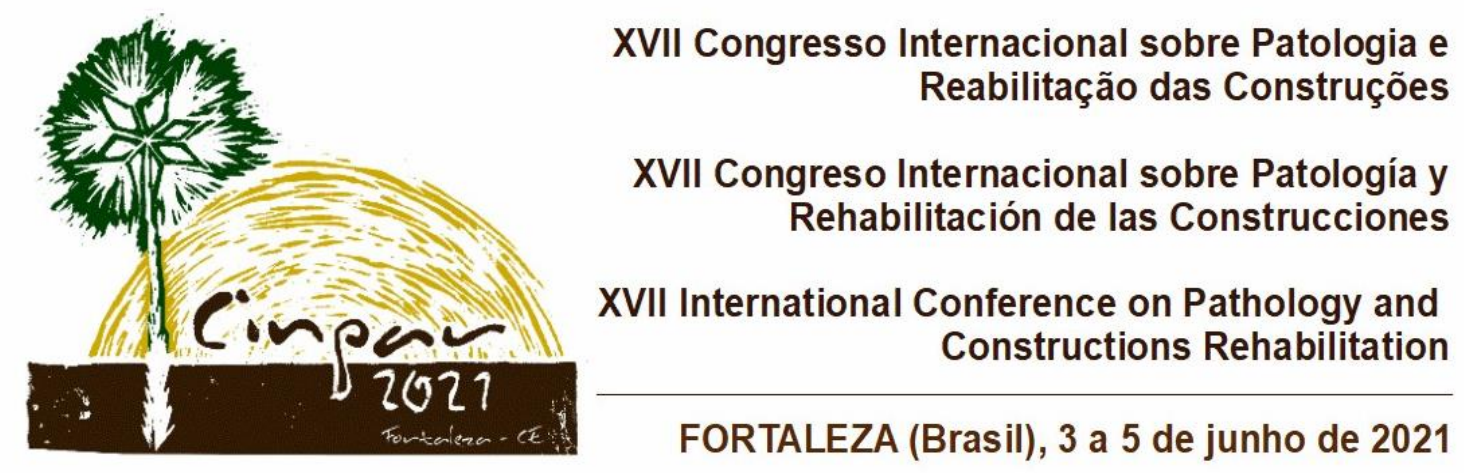

são penduradas por treliças metálicas que chegue ao destino da peça. Como resultado, as patologias se desenvolvem devido a conexão dos elementos, as juntas de dilatação, grau de protensão que o exigido é de $20 \%$ a $30 \%$ uma taxa bem maior que no caso de balaços sucessivos (MARCHETTI, 2008).

\subsection{Conceito de patologia}

Para Helene (2013), a patologia é uma parte da engenharia que faz o estudo das causas, origens e a natureza dos defeitos e as possíveis falhas que possa vir a surgir nas edificações. É considerado patologia na construção quando um determinado edifício não atende às suas funções da forma que foi projetado, e assim qualquer tipo de doença pode começar a aparecer na edificação, e a mesma começar a apresentar "sintomas" como fissuras, rachaduras, manchas por excesso de umidade, eflorescência, corrosão de armadura e trincas, mostrando que há algo errado.

E essas patologias podem ser superficiais, quando não chegam na parte estrutural, apenas na parte de acabamento, e em casos mais graves, chegam a atingir a parte estrutural e fundações.

Segundo Capello (2010), os problemas ocasionados pelas patologias devem ser provenientes de uma das etapas da construção que são integradas no processo da construção de uma edificação, ou seja, pode ser por falha de uma das etapas que faz parte do ciclo da execução. Os erros mais comuns que podem ocorrer na execução são: matérias de baixa qualidade, erros no projeto, falhas na hora de fazer a execução e as manutenções que são insuficientes e, na maioria das vezes, nem existe. Na sua grande maioria as principais causas são: variações térmicas, cargas exageradas, ou seja, que não foram previstas durante o dimensionamento, agentes biológicos, mudança de umidade, incompatibilidade dos materiais e os agentes atmosféricos, que também estão relacionados a outros acontecimentos que acabam influenciando no surgimentos de algumas anomalias.

Como o grande avanço na indústria da construção civil, é possível encontrar inúmeras falhas na execução de várias obras. E pode-se perceber que os problemas analisados nessas construções poderiam ter sido evitados com o uso adequado de matérias e aplicação de conhecimentos mais amplos das técnicas de construção e seus processos (HEERDT,2016). 


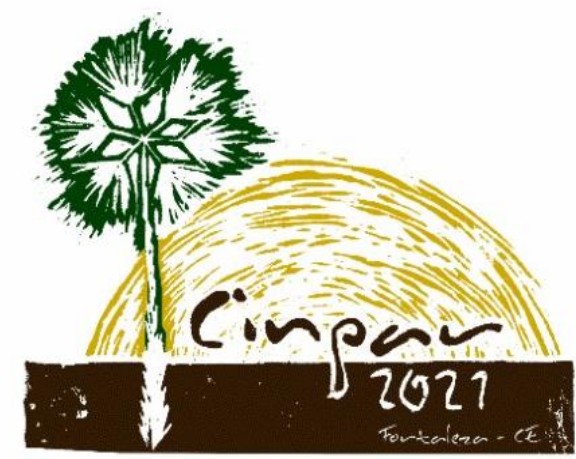

XVII Congresso Internacional sobre Patologia e
Reabilitação das Construções

XVII Congreso Internacional sobre Patología y

Rehabilitación de las Construcciones

XVII International Conference on Pathology and

Constructions Rehabilitation

FORTALEZA (Brasil), 3 a 5 de junho de 2021

\subsection{Manutenção e inspeção visual em obras públicas}

A manutenção é basicamente preventiva e representa a realização de uma inspeção e recuperação ou tenha a troca de partes defeituosas, e tenha a utilização da aplicação de processos que venham a possibilitar a conservação estrutural em bom estado. Estes reparos devem acontecer de forma periódica e priorizada, pois, vai garantira a durabilidade da estrutura (CARNEIRO, 2018).

Segundo Souza e Ripper (1998), a manutenção segue quando uma etapa é realizada após a inauguração e durante a efetiva utilização da estrutura. É definido como manutenção o conjunto de técnicas, práticas e rotinas necessárias para o bom desempenho da estrutura.

Para Lantas (2010), o uso dessa manutenção adequada da edificação, é uma condição de suma importância para a vida útil da estrutura. A falta de manutenção regular nas patologias de um nível baixo de custo de manutenção, faz com que tenha evolução e assim tendo que comprometer toda a qualidade estética da obra, tornando-a insegura e com um alto valor para maior mantê-la.

Para que haja tal sucesso é necessário que tenha uma organização, um planejamento, uma manutenção, as reformas e as fiscalizações na execução de serviços etc., com toda essa falta e outros procedimentos, é o que faz surgir as chamadas manifestações patológicas, que começam a gerar os problemas estéticos e podem comprometer também o seu uso de desempenho nas pontes.

\subsection{Método GUT}

Gravidade, Urgência e Tendência-GUT é uma ferramenta utilizada para definir prioridades, onde são dadas várias alternativas de ação, onde o mesmo tende a responder as seguintes perguntas: "O que deve ser feito primeiro?" ou "Por onde começar?". Meireles (2001), certifica responder todas as perguntas, e através disto será possível ter um alcance para classificar a importância das ações, levando em conta a gravidade, a urgência e a tendência do caso, escolhendo assim uma decisão mais cômoda e menos desfavorável à situação.

O Método GUT foi criando por Kepner e Tregoe em 1980, com a necessidade de resolver os problemas complexos nas indústrias americanas e japonesas. E no decorrer de tudo isso pode aparecer 


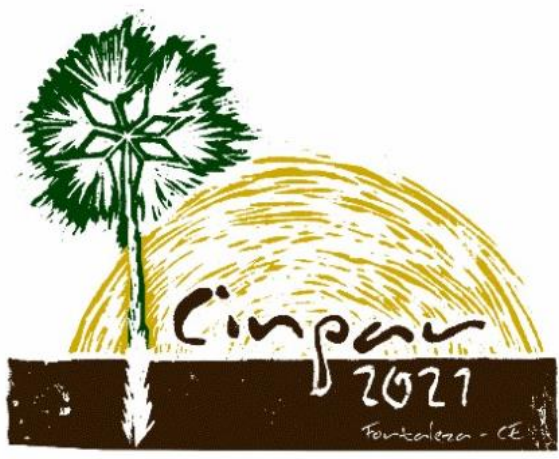

XVII Congresso Internacional sobre Patologia e
Reabilitação das Construções

XVII Congreso Internacional sobre Patología y Rehabilitación de las Construcciones

XVII International Conference on Pathology and Constructions Rehabilitation

FORTALEZA (Brasil), 3 a 5 de junho de 2021

muitos obstáculos em uma organização, e nem sempre será possível resolver todas ao mesmo tempo. (KEPNER; TREGOE,1991)

Levando em consideração a importância do cenário na qual as manifestações patológicas irão agir e que acrescentam principalmente nas obras públicas, o método GUT (Gravidade, Urgência e Tendência) tem como foco principal apontar as possíveis falhas na edificação de forma a estabelecer uma ordem crescente de prioridades para tomar medidas corretivas de 1 a 5.

De acordo Periard (2011), uma das vantagens principais para se aplicar a Matriz GUT é que ela ajuda o gerente a avaliar de forma somatória os problemas da empresa, e assim faz com que se faça possível priorizar as ações corretivas e preventivas para o extermínio total ou parcial do problema. Gravidade mostra o impacto do problema investigado caso ele venha a acontecer; Urgência serve para mostrar o período, o tempo disponível ou necessário para resolver um determinado problema analisado; Tendência é para representar o potencial de crescimento do problema, ou a chance que o problema tem para se tornar maior com o passar do tempo, como mostra na (Tabela 01) abaixo.

Tabela 01: Matriz de prioridade.

\begin{tabular}{|c|c|c|c|}
\hline Nota & Gravidade & Urgência & $\begin{array}{c}\text { Tendência } \\
\text { ("se nada for feito...") }\end{array}$ \\
\hline 5 & extremamente grave & precisa de ação imediata & ...irá piorar rapidamente \\
\hline 4 & muito grave & é urgente & ...irá piorar em pouco tempo \\
\hline 3 & grave & o mais rápido possível & ...irá piorar \\
\hline 2 & pouco grave & pouco urgente & ...irá piorar a longo prazo \\
\hline 1 & sem gravidade & pode esperar & ...não irá mudar \\
\hline
\end{tabular}

Fonte: Periard (2011).

O objetivo desta ferramenta gerencialmente é para fazer a utilização para priorizar a tomada decisão, e tudo isso levando em consideração a gravidade, a urgência e a tendência do evento relacionado. E com base nessas variáveis, o gestor pode agir com base em um escalonamento, no qual será identificado as complicações que possivelmente será resolvida primeiro. O maior diferencial do Método GUT, com base nos outros, é a simplicidade de utilização e a possibilidade de atribuir valores para cada caso concreto de maneira objetiva (MEIRELES, 2001). 


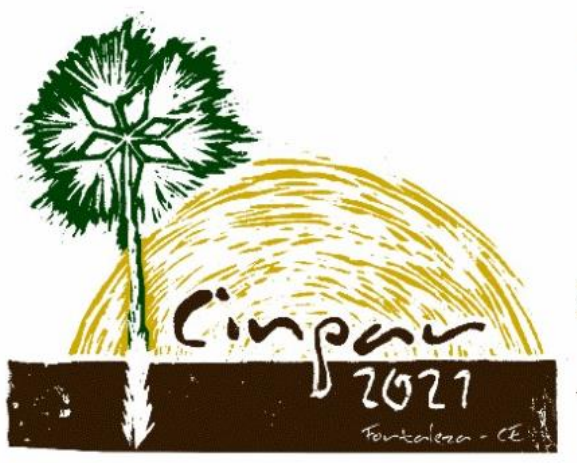

XVII Congresso Internacional sobre Patologia e
Reabilitação das Construções

XVII Congreso Internacional sobre Patología y

Rehabilitación de las Construcciones

XVII International Conference on Pathology and

Constructions Rehabilitation

FORTALEZA (Brasil), 3 a 5 de junho de 2021

O método de GUT é uma matriz na qual pode ser utilizada de forma fácil para qualquer estabelecimento. E ela possibilita evidenciar os problemas mais sérios e que necessitam de uma atenção maior. E sem esquecer que este método ajuda na elaboração de um planejamento estratégico para que possam ser solucionados.

\section{Materiais e métodos}

\subsection{TIPO DE ESTUDO}

De acordo com Yin (2001), o estudo de caso é uma estratégia de pesquisa detalhada na qual se desenvolve hipóteses teóricas com base em fontes de evidência orientando-as na coleta e análise de dados. A pesquisa é descritiva pois o tipo de pesquisa é baseado em estudo, analise, registro e observação de fatos do mundo real sem a interferência do pesquisador (BARROS E LEHFELD, 2007).

Em relação aos procedimentos do trabalho, a características do estudo é um estudo de caso, por se tratar de um estudo em profundidade, o objetivo é obter uma compreensão ampliada de outros casos semelhantes, e buscar auxiliar no entendimento por meio de referências citadas na literatura (CERVO E BERVIAN, 1983).

\subsection{LOCAL DE ESTUDO}

Esta pesquisa foi realizada em duas pontes da cidade de Caxias, Maranhão, localizada na região Nordeste do país. A cidade possui uma população de 165.525 habitantes, é cortada pelo Rio Itapecuru, e as pontes para cidade são de extrema importância (IBGE,2020).

Ambas as pontes são de suma importância para a cidade por serem as únicas que ligam dois grandes bairros ao centro. A primeira ponte Eugênio Barros, conhecida popularmente, com a ponte de cimento ou ponte da Trezidela, fica localizada na Avenida Nereu Bittencourt. A segunda ponte é Dr. Fernando Sarney é caracterizada, quanto ao tipo estrutural, como tipo viga, localizada na Avenida Luiz Sales, a ponte é mais conhecida popularmente como Ponte Nova.

Figura 03: Ponte Eugêncio Barros 


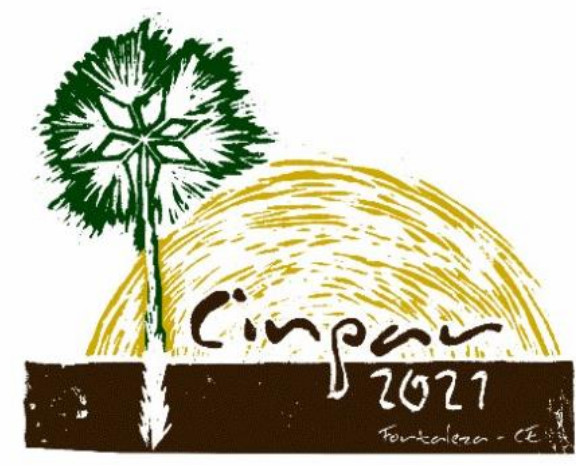

\section{Congresso Internacional sobre Patologia e Reabilitação das Construções}

\section{Congreso Internacional sobre Patología y} Rehabilitación de las Construcciones

\section{International Conference on Pathology and} Constructions Rehabilitation

FORTALEZA (Brasil), 3 a 5 de junho de 2021

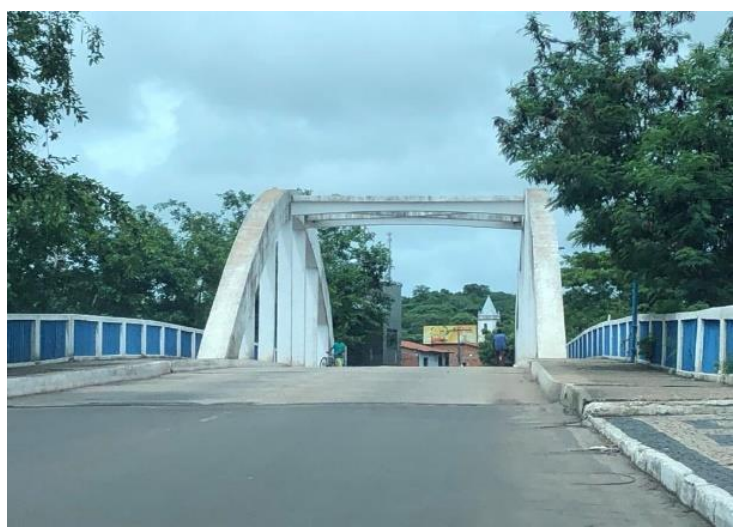

Fonte: Autor (2021)

Figura 04- Ponte Dr. Fernando Sarney

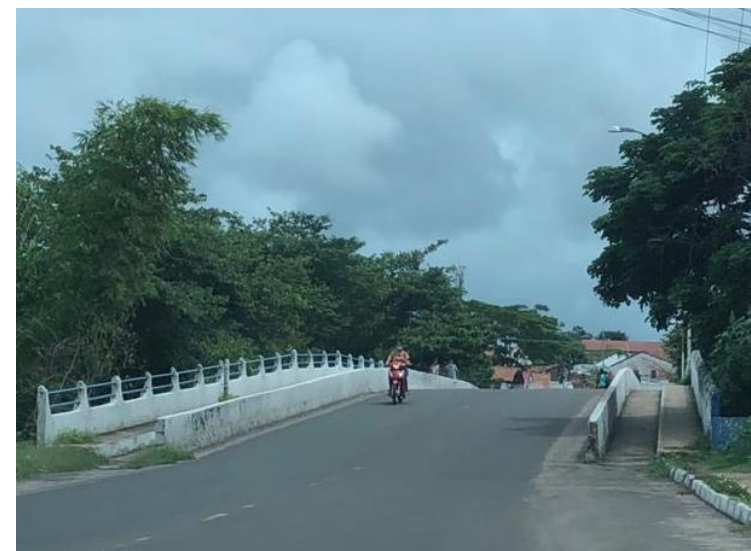

Fonte: Autor (2021)

\subsection{COLETA DE DADOS}

A pesquisa realizada é um estudo de caso e o mesmo levou em consideração as condições das obras públicas na qual estão instaladas as pontes, com o intuito de visualizar a identificação das manifestações patológicas presentes. 


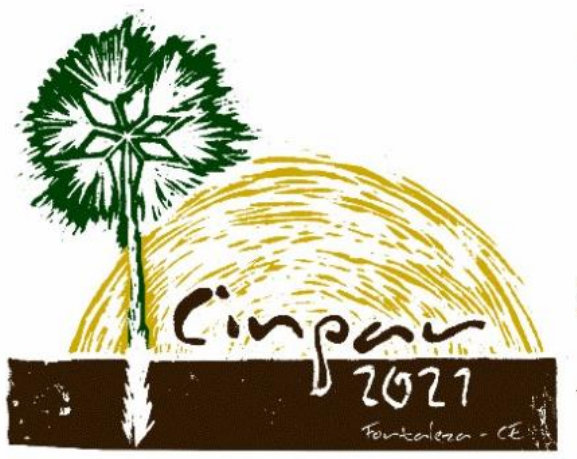

XVII Congresso Internacional sobre Patologia e
Reabilitação das Construções

XVII Congreso Internacional sobre Patología y

Rehabilitación de las Construcciones

XVII International Conference on Pathology and

Constructions Rehabilitation

FORTALEZA (Brasil), 3 a 5 de junho de 2021

É necessário obter uma fundamentação teórica e o avanço dos objetivos, iniciou-se com uma revisão bibliográfica sobre as Patologias das Construções, na qual mostra a importância do tema e as suas manifestações típicas referentes ao material avaliado. E para complementar o trabalho foi realizado uma análise bibliográfica sobre a Matriz GUT, mostrando sua utilidade em diversas áreas e suas vantagens de utilização. Junto à revisão bibliográfica, uma técnica não construtiva de inspeção visual foi utilizada para as avaliações e as características visuais em função da presença de manifestações patológicas, houve a coleta de dados e registros fotográficos das mesmas.

\subsection{EQUIPAMENTOS UTILIZADOS}

Para a pesquisa de campo foi necessário utilizar alguns materiais: pracheta, lápis, caneta, escalímetro, trena manual e câmera fotográfica.

E depois de coletar todas as informações possíveis para visualizar as maiores ocorrências, e assim identificando e caracterizando as manifestações patológicas. Foram observados e registrados os defeitos que estavam em evidência nas pontes em estudo, é necessário analisar para que possa indicar as possíveis causas que desencadearam os aparecimentos das mesmas, e por fim estabelecer um grau de prioridade de intervenção como base o método GUT.

\subsection{TRATAMENTO E ANÁLISE DOS DADOS}

O trabalho foi desenvolvido um estudo de caso no qual levou me consideração a situação da obra pública, de modo a visualizar a identificação das manifestações patológicas presentes. Foi feito uma lista para identificar e quantificar as patológicas que estavam mais visíveis no decorrer da vistoria feita nas pontes Eugênio Barros e Dr. Fernando Sarney.

E para obter informações foi necessário ter uma estrutura teórica, de modo a realizar análises e observações apropriadas de forma adequada, foram utilizados livros, artigos, dissertações e normas que falam sobre o assunto exposto, e certificando a importância do tema e as manifestações mais comuns referentes ao material avaliado.

\section{Resultados e discussões}




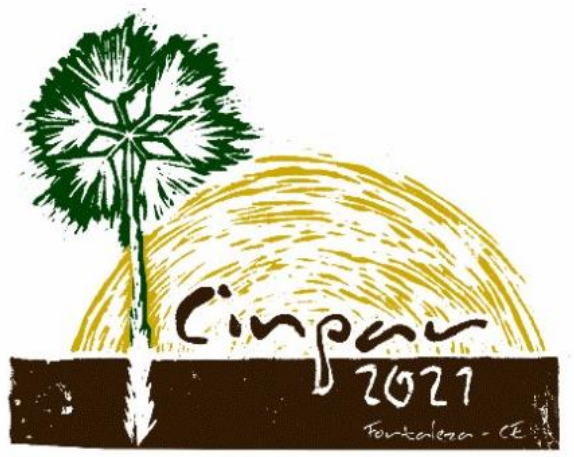

\section{Congresso Internacional sobre Patologia e Reabilitação das Construções}

\section{Congreso Internacional sobre Patología y Rehabilitación de las Construcciones}

\section{International Conference on Pathology and} Constructions Rehabilitation

\section{FORTALEZA (Brasil), 3 a 5 de junho de 2021}

O presente trabalho tem como finalidade o estudo de determinar as manifestações patológicas existentes nas duas principais ponte Pontes Eugênio Barros e Dr. Fernando Sarney em Caxias-MA, mas por meio da inspeção visual executada nas foram constatadas inúmeros tipos de manifestações patologicas. Com isso os resultados obitidos foram agrupados de acordo com os principais tipos de manifestações patologicas detecdadas: corrosão da armadura, desagregação, ninhos de concretagem, mofo, bolor, fissuras, rachaduras e trincas, as quais será representadas a seguir.

Foi possível detectar patologias em mais de 250 pontos distintos nas pontes, com formas e dimensões diferentes. $O$ resultado é apresentado na (Tabela 02), mostrando a quantidade e a porcentagem que cada anomalia teve em ordem crescente de incidência.

Tabela 02- Periodicidade por tipo de manifestação patológica

\begin{tabular}{|l|c|c|}
\hline TIPO & QUANTIDADE & PORCENTAGEM \\
\hline Corrosão da armadura & 63 & $25,2 \%$ \\
\hline Desagreação & 45 & $18 \%$ \\
\hline Ninhos de concretagem & 50 & $20 \%$ \\
\hline Fissuras, Trincas e Rachaduras & 92 & $36,8 \%$ \\
\hline TOTAL & 250 & $100 \%$ \\
\hline
\end{tabular}

Fonte: Autor (2021)

\subsection{CORROSÃO DA ARMADURA}

A corrosão ilustrada na imagem ocorre no pilar de modo bem acentuada, pois mostra que a armadura está com a sua seção bem comprometida. De modo que toda a estrutura de concreto que cobre a armadura sofre com o processo, que inicia com a fissuração em decorrencia da expansão que o aço gera.

São varios os fatores que envolvem a estrutura das pontes, ocasionando as manifestações patológicas. Na visão de Vitório (2003) as chuvas que ocorrem sobre as pontes, acaba prejudicando o concreto através da concentração de água por um tempo prologado, além da ausencia de elementos como, a deficiência de juntas e dispositivos de drenagem do tabuleiro, vulneráveis aos processos de corrosão, como acontece nas duas pontes principais analisadas em Caxias-MA.

Figura 05- Corrosão da Armadura 


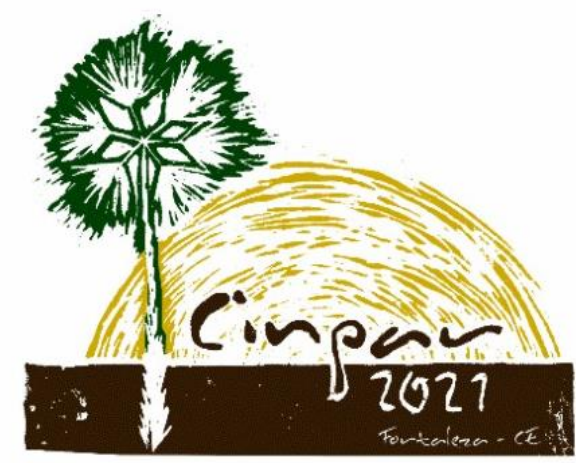

\section{Congresso Internacional sobre Patologia e Reabilitação das Construções}

\section{Congreso Internacional sobre Patología y Rehabilitación de las Construcciones}

\section{International Conference on Pathology and} Constructions Rehabilitation

FORTALEZA (Brasil), 3 a 5 de junho de 2021

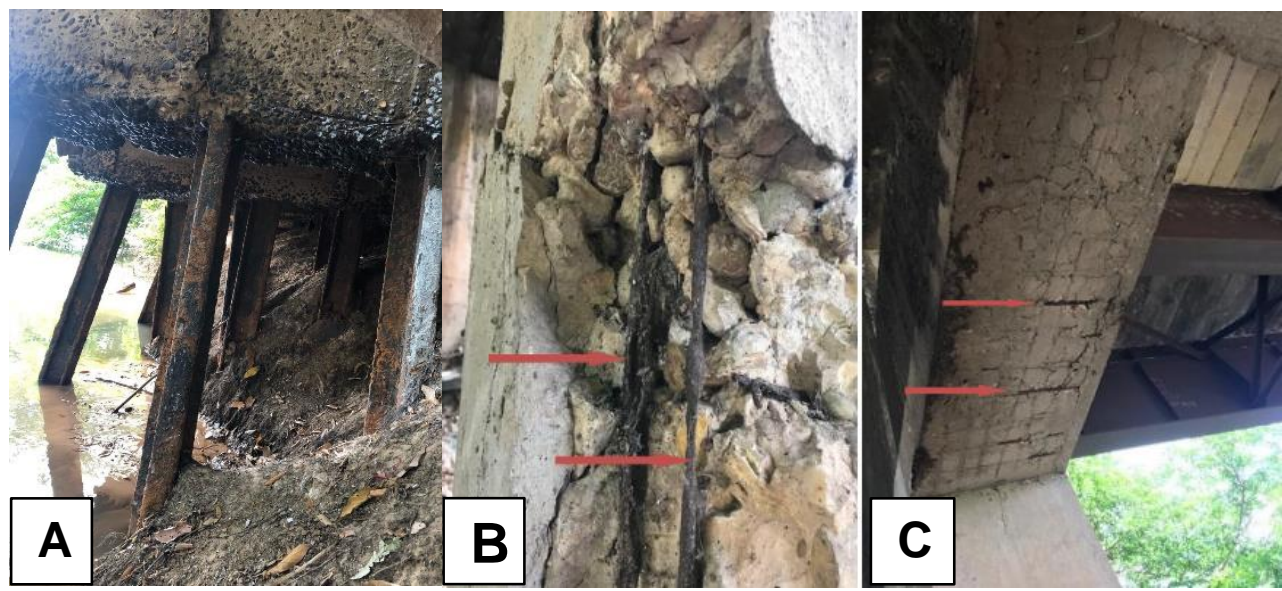

Fonte: Autor (2021)

\subsection{DESAGREGAÇÃO}

Durante a vistoria foram observada principalmente no guarda corpo da ponte, local de maior incidência, como mostra figura. São provocadas por ataques químico expansivo devido aos componentes intrínsecos ao concreto ou pela baixa resistência do mesmo, tem uma diminuição da massa, ocorrendo, assim, a desagregação do concreto. Esse tipo de manifestação patologica é caracterizada por fazerem com que os agregados fiquem mais faceis para remoção.

Para Lichtenstein (1985) afirma que as consequências da desagregação é uma peça na qal vai perder sua capacidade de resistir aos esforços que a solicitam. E o processo da desagregação é estabelicidi pela eliminação de fragmentos ou placas de concreto com a perda de monolitismo e da fixação do cimento, deixando os agregados soltos.

Figura 06- Desagregação 


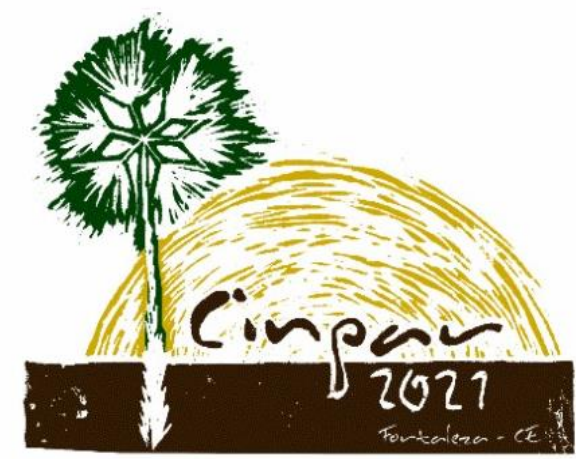

\section{Congresso Internacional sobre Patologia e Reabilitação das Construções}

\section{Congreso Internacional sobre Patología y Rehabilitación de las Construcciones}

\section{International Conference on Pathology and} Constructions Rehabilitation

FORTALEZA (Brasil), 3 a 5 de junho de 2021

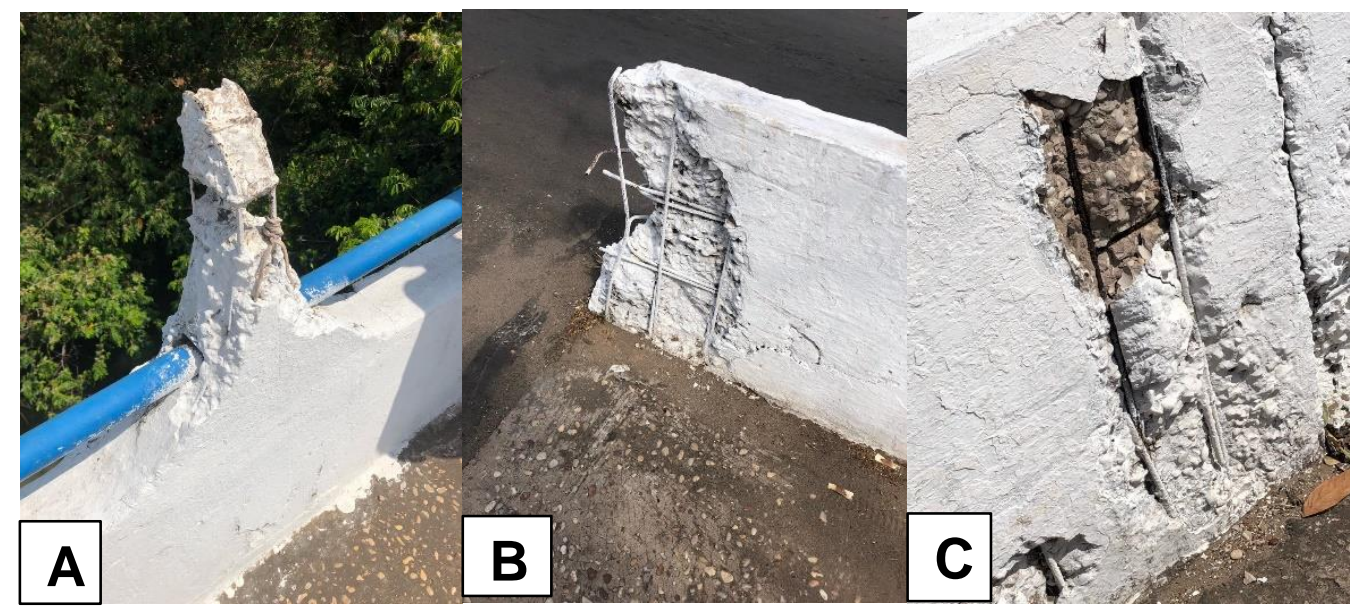

Fonte: Autor (2021)

\subsection{NINHOS DE CONCRETAGEM}

São conhecidos popularmente como bicheiras, e este problema pode influênciar na durabilidade e resistência das estruturas de concreto armado, e este processo de concretagem é caracterizado pelas negligências, nas falhas que acontecem no detalhamento de armadura e no arremesso e adensamento do concreto (FIGUEROLA, 2006). E é muito comum esse tipo de manisfestação patologica mais presente em locais que não foram preenchidos completamente com cocreto, de forma a tornar a sua superficie porosa e com alguns vazios, que tem diferentes caracteristicas das bolhas de ar aprisionado.

Figura 07- Ninhos de Concretagem

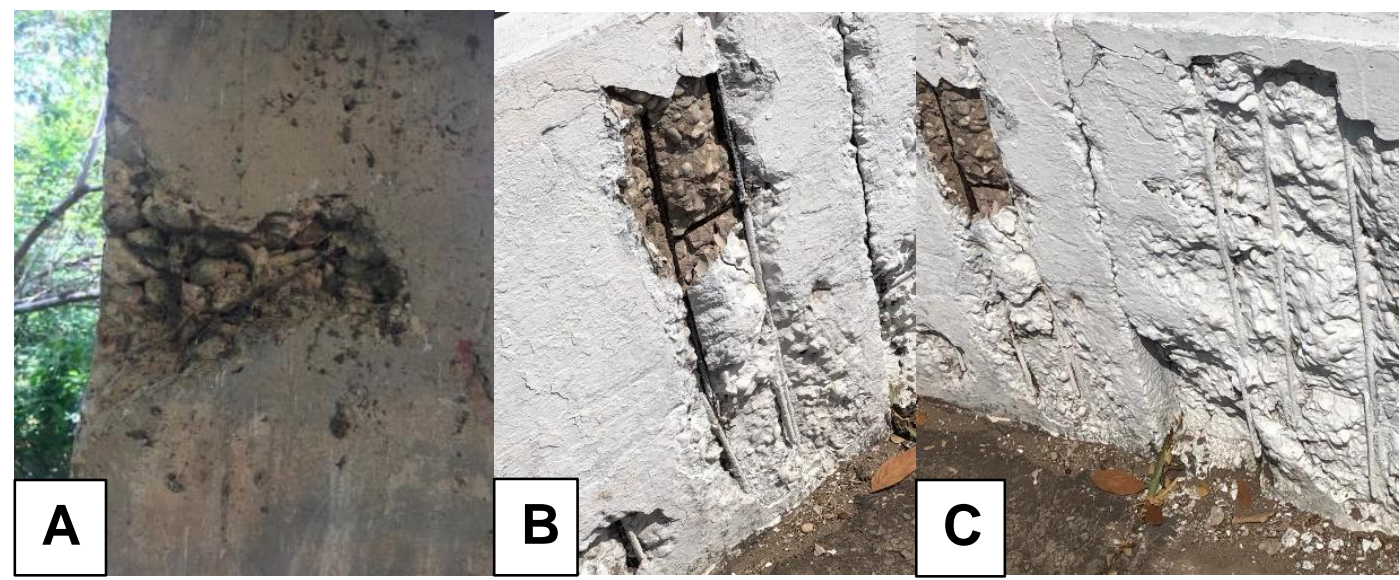

Fonte: Autor (2021) 


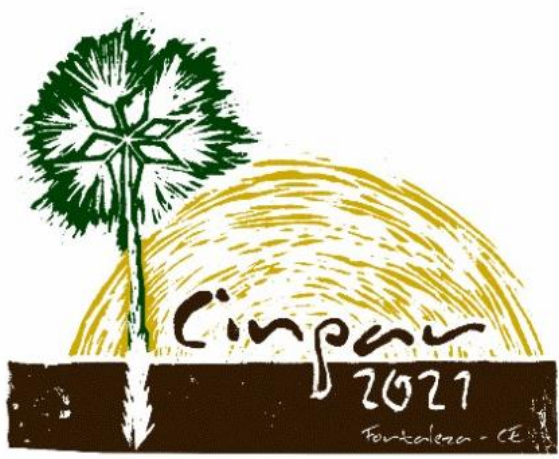

\section{Congresso Internacional sobre Patologia e Reabilitação das Construções}

\section{Congreso Internacional sobre Patología y Rehabilitación de las Construcciones}

\section{International Conference on Pathology and} Constructions Rehabilitation

FORTALEZA (Brasil), 3 a 5 de junho de 2021

\subsection{TRINCAS, FISSURAS E RACHADURAS}

Segundo Lourenço et al. (2009) fala que as ocorrências de fissuras é um fenômeno bastante genérico encontrado nas pontes de concreto armado no mundo todo. A origem está relacionada a uma estruturação irregular de tensões no interior da estrutura, que pode surgir a partir da decomposição ou desagregação do concreto. O método de fissuração pode originar graves eventos de desestabilização estrutural, onde as consequências são imensuráveis.

Figura 08- Trincas, Fissuras e Rachaduras

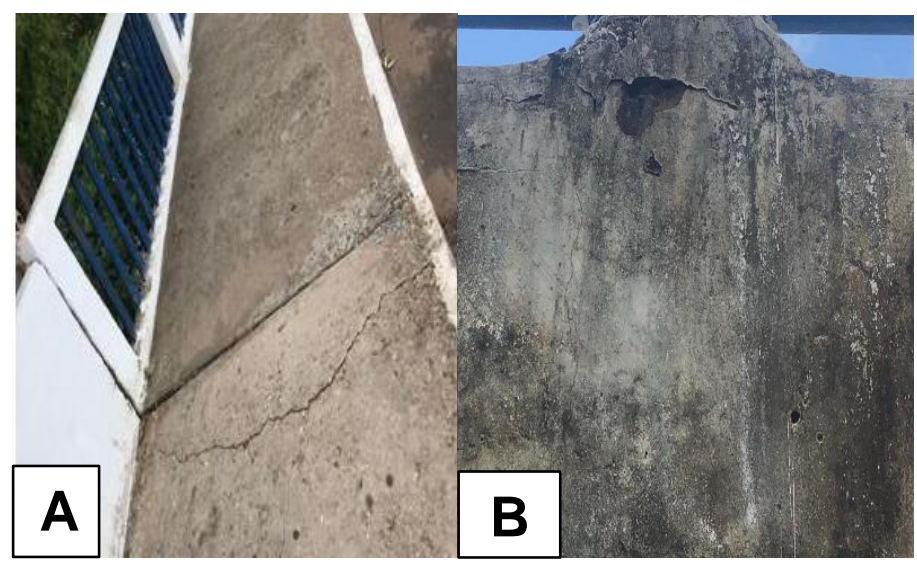

Fonte: Autor (2021)

\subsection{APLICAÇÃO DO MÉTODO GUT}

Depois de mostrar as manifestações patologicas, mostarem a aplicação do método GUT, para saber a gravidade, urgência e tendência de cada manifestação patológica de forma a determinar o grau de prioridade de intervenção das mesmas. A tabela 03 a seguir, foi classificadas as manifestações patológicas caracterizadas no estudo de caso conforme as variáveis do método GUT.

Tabela 03: Matriz de aplicação pelo método GUT

\begin{tabular}{|l|l|l|l|l|l|}
\hline Manifestação Patológica & G & U & T & GUT & Grau de priorização \\
\hline
\end{tabular}




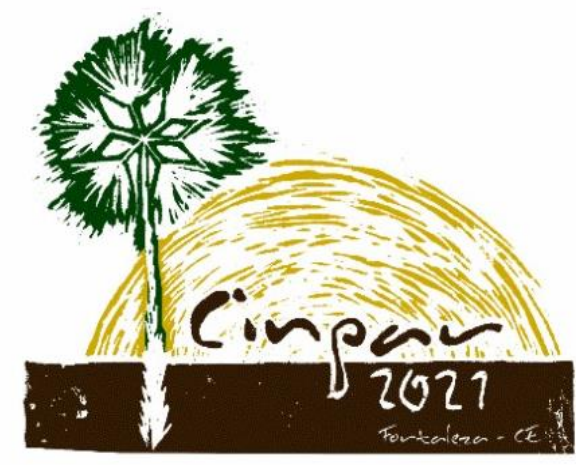

XVII Congresso Internacional sobre Patologia e
Reabilitação das Construções

XVII Congreso Internacional sobre Patología y

Rehabilitación de las Construcciones

XVII International Conference on Pathology and

Constructions Rehabilitation

FORTALEZA (Brasil), 3 a 5 de junho de 2021

\begin{tabular}{|l|l|l|l|l|l|}
\hline Corrosão da armadura & 4 & 3 & 4 & 48 & 10 \\
\hline $\begin{array}{l}\text { Fissuras, Trincas e } \\
\text { Rachaduras }\end{array}$ & 3 & 3 & 4 & 36 & 20 \\
\hline Ninhos de Concretagem & 3 & 3 & 2 & 18 & 30 \\
\hline Desagregação & 2 & 2 & 3 & 12 & 40 \\
\hline
\end{tabular}

Fonte: Autor (2021)

\section{Conclusões}

O presente trabalho possibilitou uma analise bem rebuscada sobre as manifestações patologicas encontradas nas pontes do municipio de Caxias as quais tiveram um estudo aprofudado de inspeção visual. E por meio disto fica visivel que as manifestações patologicas vista nas pontes estudadas e diante do projeto conseguimos elaborar planos de recuperação e tratamento da estrutura. Nessa perspectiva, notou-se que ambas as pontes têm manifestações patologicas começando das mais simples até as mais complexas de serem tratadas, podendo destacar a maioria do tipo trincas,oxidação, fissuras, desplacamento do revestimento e armação exposta corroídas.

Aconselha-se que haja uma substituição do revestimento dos passeios em questão que em sua grande maioria aparece solto e com trincas devido as altas temperaturas da cidade. É importante observar um realinhamento do guarda corpo no qual se encontra em desaprumo e a mudança dos corrimões que encontra-se oxidados, a adição do sistema de drenagem, o tratamento das armações exposta no tabuleiro da ponte, e se for possivel, adição de uma psita de rolamento na qual vai servir para receber diretamente os 


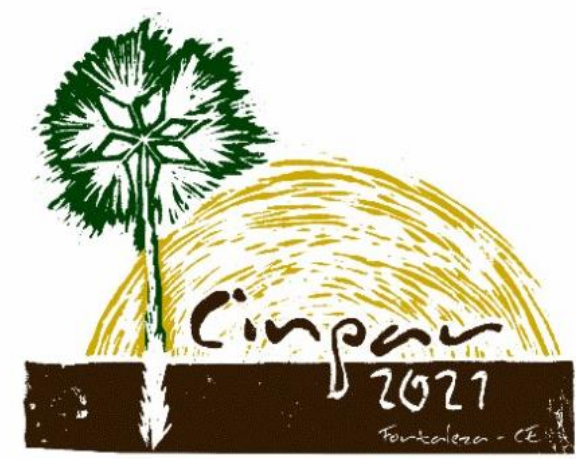

XVII Congresso Internacional sobre Patologia e
Reabilitação das Construções

XVII Congreso Internacional sobre Patología y Rehabilitación de las Construcciones

XVII International Conference on Pathology and Constructions Rehabilitation

FORTALEZA (Brasil), 3 a 5 de junho de 2021

esforços gerados pelos automóveis, uma reforma bem rebuscada do reforço das denfensas da ponte que se encontra com perdas de grandes seções.

De forma a quanto à superestrututura da ponte vistoriada durante a obra, pode-se verificar que o processo de deterioração das peças pode ser devido a motivos químicos, que são causados pela pentração de água nas peças, ou por motivos físicos, o crescimento do tráfego de veículos e sobrecarga de estruturas de pontes. As transversinas, longarinas e pilares confirmam que as barras de aço não estão suficientemente cobertas e as barras de aço expostas não estão suficientemente oxidadas. Para isso, o quadro deve ser processado imediatamente e coberto. E vale ressaltar que todas as recomendações são baseadas na experiência, pois o trabalho é baseado em inspeção visual, sem o uso de amostragem para pesquisas mais aprofundadas, e assim fica impossivel tirar conclusões especificas sobre o estado das pontes e suas condições patológicas que danificam sua capacidade de carga.

Com a realização deste trabalho não foi possivel extrair dados e informações sobre a existência de algum plano municipal que possa incluir a recuperação da estrutura das pontes. E por fim podemos concluir que é indispensavel um estudo mais detalhaddo das estruturas e das manifestações patologicas que estão presentes nas pontes estudadas para que haja maior exatidão de resultados. E para futuros trabalhos será realizado na estrutura da ponte que fica localizada na BR-316.

\section{Referências Bibliográficas}

.NBR 9062: Projeto e execução de estruturas de concreto pré-moldado. Rio de Janeiro, 2017.

ARAÚJO, A. Monitoramento da corrosão em estruturas de concreto: sensor de umidade, de taxa de corrosão e de fibra óptica. São Paulo: Téchne 195, 2013.

BARROS, A. J. S.; LEHFELD, N. A. S. Fundamentos de Metodologia Científica. 3. Ed. São Paulo: Pearson Prentice Hall, 2007.

BAUER, R. J. F. Patologia em revestimentos de argamassa. SIMPÓSIO BRASILEIRO DE TECNOLOGIA DA ARGAMASSA, 1997, Salvador. Disponível em: <https://www.gtargamassas.org.br/eventos/file/69-patologiaem-revestimento-de-argamassa-inorganica>. Acesso em: 15 set. 2020 


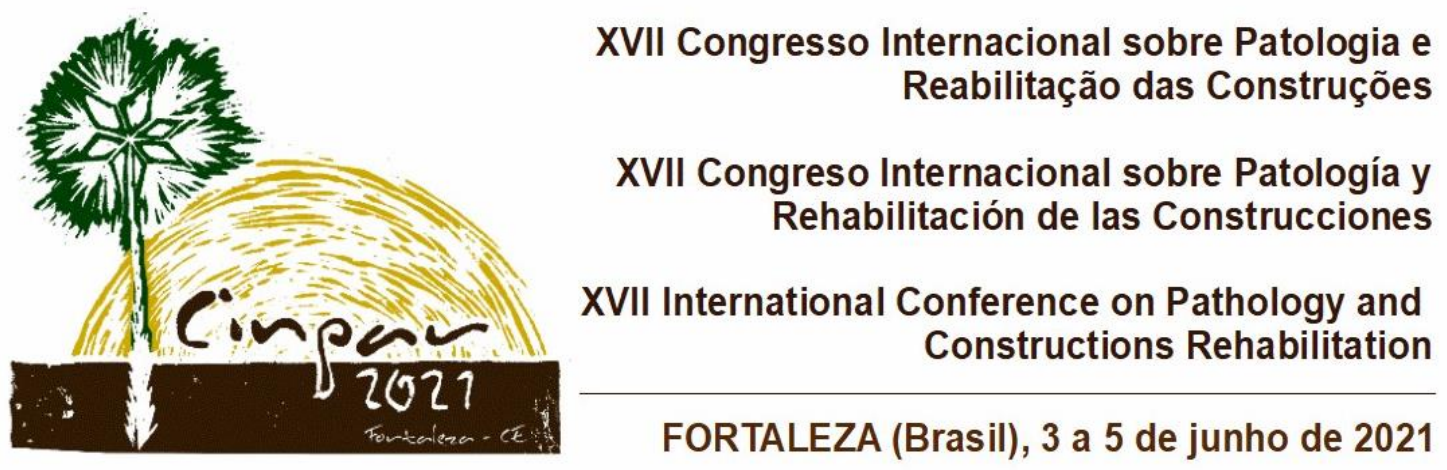

BRASIL. TCU - Tribunal de Contas da União. Secretaria de Controle Externo. Secretaria de fiscalização de obras de infraestrutura urbana. Obra públicas: recomendações básicas para a contratação e fiscalização de obras de edificações públicas. Brasília, 2014. 4ạ ed.

BRITO, T. F. Análise de manifestações patológicas na construção civil pelo método gut: estudo de caso em uma instituição pública de ensino superior. João Pessoa, jun. 2017. Disponível em: $<$ https://security.ufpb.br/ccec/contents/documentos/tccs/2016.2/analise-de-manifestacoes-patologicasna-construcao-civil-pelo-metodo-gut-estudo-de-caso-em-uma-instituicao-publica-de-ensino-superior.pdf>. Acesso em: 05 out. 2020.

CAPELLO, A. Patologia das fundações. Scribd, Jundiaí, 2010. Disponível em: <https://pt.scribd.com/doc/54137409/patologia-de-fundacoes-tcc>. Acesso em: 15 ago. 2020.

CARNEIRO, J. S., GUIMARÃES, M. S. ROCHA, G. S. FERREIRA, C. V. Inspeção Predial: Estudo de caso de uma unidade escolar no município de Caxias - MA. Anais do Congresso Brasileiro de Patologia das Construções CINPAR 2018, Campo Grande - MS, abril 2018.

Cavalcante, G. H. F., Ponte em concreto armado: análise e dimensionamento/ Gustavo Henrique Ferreira Cavalcante. São Paulo: Blucher, 2019. 462 p.: il.

CERVO, A. L. e BERVIAN, P. A. (1983) Metodologia Científica: para uso dos estudantes universitários. 3.ed. São Paulo: McGraw-Hill do Brasil.

CORSINI, R. Trinca ou fissura? Téchne. 160. Jul. de 2010. Disponível em: $<$ http://techne.pini.com.br/engenharia-civil/160/trinca-ou-fissura-como-se-originam-quais-os-tipos285488-1.aspx>. Acesso em: 15 ago. 2020.

FELIPPE FILHO, W. N. Avaliação dos coeficientes de impacto utilizados no cálculo de pontes rodoviárias via análise dinâmica de estruturas. $47 \mathrm{f}$. Trabalho de graduação (Engenharia Civil), Universidade Federal de Juiz de Fora, Juiz de Fora, 2008.

HEERDT, G. B. Principais patologias na construção civil. Academia, 2016. Disponível em: <https://www.academia.edu/31785497/principais_patologias_na_construção_civi>l. Acesso em: 16 ago. 2020.

FIGUEROLA, V. Vazios de concretagem: cuidados especiais com a armação e uso de produtos para alterar características do concreto podem evitar a formação das "bicheiras".

HELENE, P. R. L. A nova nb 1 /2003 (nbr 6118) e a vida útil das estruturas de concreto. Artigo Técnico. Disponível em < http://www.phd.eng.br/wpcontent/uploads/2014/06/185.pdf>. Acesso em 28 mar. 2021. 


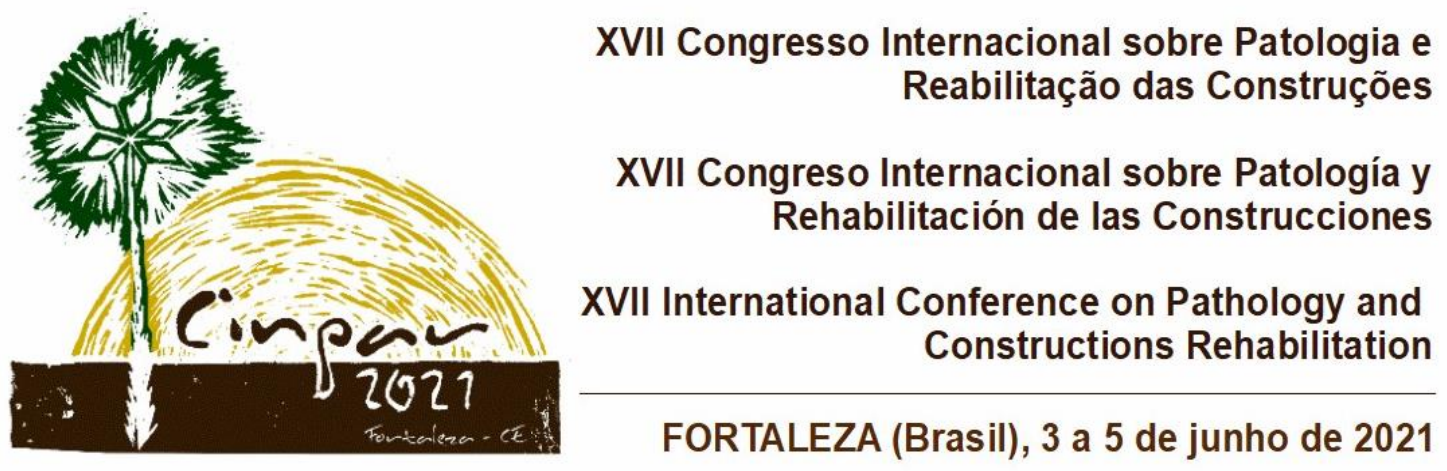

IBGE - INSTITUTO BRASILEIRO DE GEOGRAFIA E ESTATístICA. Disponível em: < https://cidades.ibge.gov.br/brasil/ma/caxias/panorama>. Acesso em: 24 nov. 2020.

IBAPE - INSTITUTO BRASILEIRO DE AVALIAÇÕES E PERÍCIAS DE ENGENHARIA. Inspeção e Manutenção Predial. Paraná: Ibape, 2016. Disponível em: http://177.92.30.55/ws/wp-content/uploads/2016/12/inspecao-e-manutencaopredial.pdf.Acesso em 28 de mar. 2021.

KEPNER, C., \& TREGOE, B. (1991). O Novo Administrador Racional. São Paulo: Makron Books.

LANTAS, L. C. Estudo de caso: análise de patologias estruturais em edificação de gestão pública. $2010.58 \mathrm{f}$. Trabalho de conclusão de curso - Universidade Federal do Paraná, Curitiba, 2010.

LICHTENSTEIN, N. B. Patologia das Construções: procedimento para formulação do diagnóstico de falhas e definição de conduta adequada à recuperação de edificações: São Paulo: Escola Politécnica da USP, 1985. Dissertação (M estrado em Engenharia Civil) - Universidade de São Paulo, 1985.

LEONHARDT, F. Construções de Concreto: princípios básicos da construção de pontes de concreto. Rio de Janeiro. Inter ciência, 1979.

LOURENÇO, L. C. et. al. Parâmetros de Avaliação de Patologias em Obras-de-Arte Especiais. 2009. Disponível em < http://www.civil.uminho.pt/revista/artigos/n34/Pag_5- 14.pdf>. Acesso em 28 mar. 2021

LOTTERMANN, A. F. Patologias em estruturas de concreto: estudo de caso. ljuí/RS, 2015. Disponível em: <bibliodigital.unijui.edu.br:8080/xmlui/bitstream/handle/123456789/2133/trabalho\%20tcc2\%20final\%20a ndre\%20f\%20lottermann.pdf?sequence=1>. Acesso em: 24 nov. 2020.

MACHETTI, O. Pontes de Concreto Armado. 1. Ed. São Paulo. Blucher, 2008.

MEIRELES, M. Ferramentas administrativas para identificar, observas e analisar problemas. 1. ed. São Paulo: Art \& Ciência, 2001.

PERIARD, G. Matriz GUT: Guia Completo, 2011. Disponível em: <http://www. sobreadministracao.com/matriz-gut-guia-completo/>. Acesso em: 19 set. 2020.

PFEIL, W. 1979. PONTES EM CONCRETO ARMADO: ELEMENTOS DE PROJETOS, SOLICITAÇÕES, DIMENSIONAMENTOS. Livros técnicos científicos editora S.A. Rio de Janeiro.

PRADO, D. Planejamento e Controle de Projeto. Belo Horizonte MG: Editora de Desenvolvimento Gerencial ,1998. Série Gerencia de Projetos, Vol. 2

SANTOS, A. Trincas, fissuras, fendas e rachaduras exigem cuidado. IBDA. 2002. Disponível em: <http://www.forumdaconstrucao.com.br/conteudo.php?a=17\&Cod=1579>. Acesso em: 10 set. 2020. 


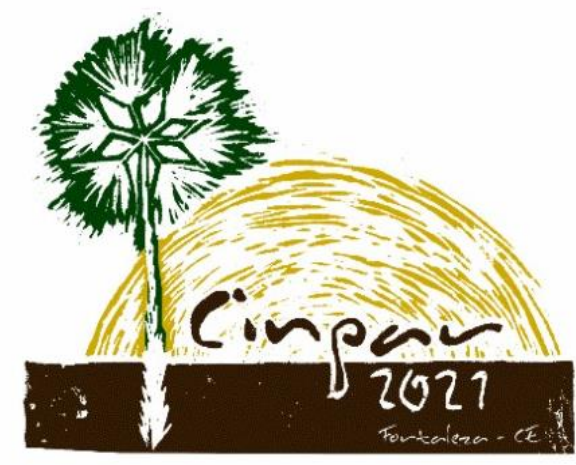

\section{Congresso Internacional sobre Patologia e Reabilitação das Construções \\ XVII Congreso Internacional sobre Patología y Rehabilitación de las Construcciones \\ XVII International Conference on Pathology and Constructions Rehabilitation \\ FORTALEZA (Brasil), 3 a 5 de junho de 2021}

Service D'Études Techniques des Routes et Autoroutes - SÉTRA. Corniches. 2002. Disponível em: < $<$ http://dtrf.setra.fr/pdf/pj/Dtrf/0000/Dtrf0000409/DT409.pdf?openerPage=notice>. Acesso em: 05 set 2020.

SOTILLE, M. Matriz GUT - gravidade, urgência e tendência. 2014. Postado em: 5 maio 2014 no Blog Dicas PMP / CAPM. Disponível em: <http://dicasgp.pmtech.com.br/matriz-gut-gravidade-urgencia-e-tendencia/>. Acesso em: 19 set. 2020.

VERÇOZA, E. J. Patologia das Edificações. Porto Alegre: Editora Sagra, 1991.

VIEIRA, M. A. Patologias Construtivas: conceito, Origens e Método de Tratamento. Revista Especialize OnLine IPOG. Goiânia, 12a ed, n. 012, jan-dez/2016.

VITÓRIO, A. Fundamentos da patologia das estruturas nas perícias de engenharia. Instituto Pernambucano de Avaliações e Perícias de Engenharia. Recife, 2003. 